\title{
EDITORIAL
}

\section{An Introduction from the Co-Chairs of the WMS Practice Guidelines Committee}

This supplement of Wilderness \& Environmental Medicine is a special issue comprised of the Wilderness Medical Society (WMS) Practice Guidelines (PG) published to date. Each PG has been updated from its previous version in an attempt to keep our series as current and evidence based as possible. In addition, each supplement has an associated online table summarizing the literature on which our recommendations are based. All recommendations are graded based on clinical strength as outlined by the American College of Chest Physicians (Table). ${ }^{1}$

Clinical Practice Guidelines (CPGs) have become ubiquitous as the database of medical literature has increased exponentially over the past two decades. The explosion in medical literature has created a voluminous amount of information that is impossible for the average clinician to navigate. As a result, an increasing volume of CPGs have been published to help clinicians manage this information. Unfortunately, however, a unified and reliable approach to the development of CPGs has not yet been universally adopted. One major contributing factor to this lack of standardization is the variability of evidence across different specialties and medical conditions of widely varying incidences. Well-designed and adequately powered randomized clinical trials (RCTs) lend themselves well to situations where common ailments (eg, diabetes mellitus) can be treated dichotomously (medication vs. placebo). This is particularly true when blinding can be easily accomplished. High level evidence is far more difficult to obtain in procedural specialties (subject to large variations in technique, myriad related biases, and difficulty blinding) and rare conditions. Certainly, the latter is a challenge in austere medicine. The illnesses and injuries we treat are not only rare, but occur in challenging and remote environments. It is unlikely that we will ever amass high level evidence in the form of RCTs for the treatment of high altitude cerebral edema, high altitude pulmonary edema, venomous reptile and arthropod bites, rabies, or lightning strikes. Even more common conditions such as frostbite, acute mountain sickness, hypo- and hyperthermia, and submersion are relatively infrequent, disparate, and unpredictable.

In 2008 the Institute of Medicine (IOM) published guidelines for the development of a standardized approach for objective, scientifically valid, and consistent approaches to developing CPGs. ${ }^{2}$ In spite of these efforts, an independent review of 130 guidelines subsequently published revealed that less than half of these CPGs met more than fifty percent of the IOM standards. ${ }^{3}$

The following represents the best attempt of the WMS to develop a trustworthy CPG process, based on the principles outlined by the IOM:

Transparency. The WMS will clearly publicize the process by which CPGs are developed. Our CPG committee meetings are open to the WMS membership and our process will be delineated in editorials such as this communication.

Guidelines Development Group Composition. Guideline panel membership is a main determinant of the trustworthiness of guideline. ${ }^{4}$ Many panels are composed of authors representing a single specialty, thereby sharing similar values and biases. The WMS is committed to insuring that each CPG is developed by a working group representative not only of the best experts in the field but one that is multi-disciplinary in scope. The proposed writing panel for each WMS CPG must be approved by the entire WMS Practice Guidelines Committee, with input from the Journal's editorial staff, WMS executive committee, and WMS board of directors when necessary to insure the final panel represents the best expertise in the field. There is no requirement for panel members to be WMS members.

Conflicts of Interest. The WMS CPG development protocol requires complete disclosure of conflicts of interest of all panel members as the first order of business once a panel is formed. Panel members with a significant conflict of interest must be removed from the panel and cannot be an author. Conflicted panel members may serve in an advisory capacity only.

Use of Best Evidence Available. The WMS is committed to ensuring that each CPG panel, as a whole, possesses a sufficient level of expertise to search, identify, critique, and grade the available evidence to insure the most inclusive search and identification of the highest level of evidence. The inclusion of supplementary data tables with each PG attempts to provide further detail regarding the quality of evidence on which each recommendation is based. 
Table. American College of Chest Physicians (ACCP) classification scheme for grading evidence and recommendations in clinical guidelines

\begin{tabular}{|c|c|c|c|}
\hline Grade & Description & Benefits vs risks and burdens & $\begin{array}{c}\text { Methodological quality of supporting } \\
\text { evidence }\end{array}$ \\
\hline $1 \mathrm{~A}$ & $\begin{array}{l}\text { Strong recommendation, high-quality } \\
\text { evidence }\end{array}$ & $\begin{array}{l}\text { Benefits clearly outweigh risks and } \\
\text { burdens or vice versa }\end{array}$ & $\begin{array}{l}\text { RCTs without important limitations or } \\
\text { overwhelming evidence from } \\
\text { observational studies }\end{array}$ \\
\hline 1B & $\begin{array}{l}\text { Strong recommendation, moderate- } \\
\text { quality evidence }\end{array}$ & $\begin{array}{l}\text { Benefits clearly outweigh risks and } \\
\text { burdens or vice versa }\end{array}$ & $\begin{array}{l}\text { RCTs with important limitations or } \\
\text { exceptionally strong evidence from } \\
\text { observational studies }\end{array}$ \\
\hline $1 \mathrm{C}$ & $\begin{array}{l}\text { Strong recommendation, low-quality or } \\
\text { very low quality evidence }\end{array}$ & $\begin{array}{l}\text { Benefits clearly outweigh risks and } \\
\text { burdens or vice versa }\end{array}$ & Observational studies or case series \\
\hline $2 \mathrm{~A}$ & $\begin{array}{l}\text { Weak recommendation, high-quality } \\
\text { evidence }\end{array}$ & $\begin{array}{l}\text { Benefits closely balanced with risks } \\
\text { and burdens }\end{array}$ & $\begin{array}{l}\text { RCTs without important limitations or } \\
\text { overwhelming evidence from } \\
\text { observational studies }\end{array}$ \\
\hline 2B & $\begin{array}{l}\text { Weak recommendation, moderate- } \\
\text { quality evidence }\end{array}$ & $\begin{array}{l}\text { Benefits closely balanced with risks } \\
\text { and burdens }\end{array}$ & $\begin{array}{l}\text { RCTs with important limitations or } \\
\text { exceptionally strong evidence from } \\
\text { observational studies }\end{array}$ \\
\hline $2 \mathrm{C}$ & $\begin{array}{l}\text { Weak recommendation, low-quality or } \\
\text { very low quality evidence }\end{array}$ & $\begin{array}{l}\text { Uncertainty in the estimates of benefits, } \\
\text { risks and burden; benefits, risk and } \\
\text { burden may be closely balanced }\end{array}$ & Observational studies or case series \\
\hline
\end{tabular}

RCT, randomized controlled trial.

Source: Guyatt G, Gutterman D, Baumann MH, et al. Grading strength of recommendations and quality of evidence in clinical guidelines; report from an American College of Chest Physicians task force. Chest. 2006;129:174-181.

Among several strong guideline systems currently available, this committee believes the classification scheme developed by the American College of Chest Physicians ${ }^{1}$ (ACCP) best fits the WMS CPGs. Much of the evidence in wilderness medicine is of low-quality or small numbers, and our recommendations are made as strong or weak based more on the benefit vs. risk of an intervention rather than the quality of evidence supporting it. Among the available evidence grading systems, the ACCP guidelines offer the ability to assign grades with a clear delineation of how the strength of the recommendation is influenced by both the evidence and the risk/benefit ratio. Other systems are less clear in this regard, or seemingly equate the strength of the recommendation disproportionately to the strength of evidence. While this approach is no doubt appropriate in clinical areas where high levels of evidence exist, we believe it is less transparent in those areas where the preponderance of evidence is of lower quality.

Evidence Quality and Recommendation Strength. For each recommendation, the CPGs should provide sound reasoning, satisfactory discussion of benefits and risks, and describe the relative strength of the evidence and the role of subjective judgments. If there are differences of opinion amongst panel members, these differences should be noted and discussed.
Articulating Recommendations. CPGs should clearly articulate the action recommended and the circumstances around which the action should be taken.

External Review. All WMS CPGs are submitted to Wilderness \& Environmental Medicine and are subjected to the same rigorous single-blinded peer review process, including outside expert peer review, as any other submitted manuscript.

Updating. The WMS is committed to timely updating of all CPGs, of which this special issue is the first update since our series began. Authors are expected to keep their articles as evidence based and current as possible, thus some PGs with new or changing data may be updated more frequently than others.

We believe the process as outlined above represents the best attempt of the Society to present CPGs that are both valuable and trustworthy. Additionally, we are committed to communicating to as many "end-users" as possible to solicit feedback on the utility and effectiveness of CPG implementation and will use this data to influence subsequent updated versions of the guidelines. The previously published PGs have been some of the most widely read and highly cited articles in WEM, and we are both honored and humbled by the task of providing further guidance to our readers through future practice guidelines. 
Tracy Cushing, MD, MPH

Robert H. Quinn, MD

Co-Chairs, Wilderness Medical Society

Practice Guidelines Committee

\section{References}

1. Guyatt G, Gutterman D, Baumann M, et al. Grading strength of recommendations and quality of evidence in clinical guidelines: report from an American College of Chest Physicians task force. Chest. 2006;129:174-181.

2. IOM (Institute of Medicine). Clinical Practice Guidelines We Can Trust Washington, DC: National Academies Press; 2011.

3. Kung J, Miller RR, Mackowiak PA. Failure of clinical practice guidelines to meet the Institute of Medicine standards: two decades of little, if any, progress. Arch Intern Med. 2012;172:1628-1633.

4. Shaneyfelt T. In guidelines we cannot trust. Arch Intern Med. 2012;172:1633-1644. 